\title{
Potent Neutralization of MERS-CoV by Human Neutralizing Monoclonal Antibodies to the Viral Spike Glycoprotein
}

\author{
Liwei Jiang, ${ }^{1 *}$ Nianshuang Wang, ${ }^{2 *}$ Teng Zuo, ${ }^{1,3}$ Xuanling Shi, ${ }^{1}$ Kwok-Man Vincent Poon, ${ }^{4}$ \\ Yongkang Wu, ${ }^{5}$ Fei Gao, ${ }^{1}$ Danyang Li, ${ }^{1}$ Ruoke Wang, ${ }^{1}$ Jianying Guo, ${ }^{1}$ Lili Fu, ${ }^{1}$ Kwok-Yung Yuen, ${ }^{4}$ \\ Bo-Jian Zheng, ${ }^{4 \dagger}$ Xinquan Wang, ${ }^{2+}$ Linqi Zhang ${ }^{1 \dagger}$
}

\begin{abstract}
The recently identified Middle East respiratory syndrome coronavirus (MERS-CoV) causes severe and fatal acute respiratory illness in humans. However, no prophylactic and therapeutic agents specifically against MERS-CoV are currently available. Entry of MERS-CoV into target cells depends on binding of the receptor binding domain (RBD) of the viral envelope spike glycoprotein to the cellular receptor dipeptidyl peptidase 4 (DPP4). We report the isolation and characterization of two potent human RBD-specific neutralizing monoclonal antibodies (MERS-4 and MERS-27) derived from single-chain variable region fragments of a nonimmune human antibody library. MERS-4 and MERS-27 inhibited infection of both pseudotyped and live MERS-CoV with $\mathrm{IC}_{50}$ (half-maximal inhibitory concentration) at nanomolar concentrations. MERS-4 also showed inhibitory activity against syncytia formation mediated by interaction between MERS-CoV spike glycoprotein and DPP4. Combination of MERS-4 and MERS-27 demonstrated a synergistic effect in neutralization against pseudotyped MERS-CoV. Biochemical analysis indicated that MERS-4 and MERS-27 blocked RBD interaction with DPP4 on the cell surface. MERS-4, in particular, bound soluble RBD with an about 45 -fold higher affinity than DPP4. Mutagenesis analysis suggested that MERS-4 and MERS-27 recognized distinct regions in RBD. These results suggest that MERS-4 and MERS-27 are RBD-specific potent inhibitors and could serve as promising candidates for prophylactic and therapeutic interventions against MERS-CoV infection.
\end{abstract}

\section{INTRODUCTION}

The recently identified Middle East respiratory syndrome coronavirus (MERS-CoV) causes severe and fatal acute respiratory illness in humans (1). Symptoms include fever, cough, and shortness of breath, similar to those seen during the outbreak of severe acute respiratory syndrome (SARS) in 2003, which was caused by the coronavirus SARS-CoV (2-8). MERS-CoV and related coronaviruses have been found in several animal species such as bats and dromedary camels (9-13). Genetic and phylogenetic characterization has shown that MERS-CoV belongs to lineage $\mathrm{C}$ of the genus of Betacoronavirus and is closely related to Tylonycteris bat coronavirus HKU4 (Ty-BatCoV HKU4) and Pipistrellus bat coronavirus HKU5 (Pi-BatCoV HKU5), although the direct source and reservoirs of MERS-CoV remain uncertain $(3,5,6,9,14-20)$. The high fatality rate ( 40\%) (http://www.who.int/csr/don/2014_01_09/en/index. html) and clusters of human-to-human transmission $(21,22)$ of this deadly virus have raised global concern about the potential for a MERS pandemic. Although treatment with interferon and ribavirin improves clinical outcome of MERS-CoV-infected rhesus macaques (23), and to a lesser extent in infected human (24), no MERS-CoVspecific treatment or vaccine is currently available (25-28). Clearly,

${ }^{1}$ Comprehensive AIDS Research Center, Collaborative Innovation Center for Diagnosis and Treatment of Infectious Diseases, School of Medicine, Tsinghua University, Beijing 100084, China. ${ }^{2}$ Ministry of Education Key Laboratory of Protein Science, Center for Structural Biology, School of Life Sciences, Tsinghua University, Beijing 100084, China. ${ }^{3}$ School of Life Sciences, Tsinghua University, Beijing 100084, China. ${ }^{4}$ Department of Microbiology, The University of Hong Kong, Hong Kong, China. ${ }^{5}$ Department of Laboratory Medicine, West China Hospital, Sichuan University, Chengdu 610041, China. *These authors contributed equally to this work.

†Corresponding author. E-mail: zhanglinqi@tsinghua.edu.cn (L.Z.); xinquanwang@ mail.tsinghua.edu.cn (X.W.); bzheng@hkucc.hku.hk (B.-J.Z.) there is an urgent need for an effective antiviral therapy for this emerging global threat.

Like other coronaviruses, MERS-CoV uses its envelope spike (S) glycoprotein for interaction with a cellular receptor for entry into the target cell (4). The S glycoprotein consists of a globular S1 domain at the N-terminal region, followed by membrane-proximal S2 domain and transmembrane domain $(7,8,29-31)$. Determinants of host range and cellular tropism are located in the receptor binding domain (RBD) within the S1 domain, whereas mediators of membrane fusion have been identified within the S2 domain $(7,8,29,30)$. Through copurification with the MERS-CoV S1 domain, Raj and colleagues identified that dipeptidyl peptidase 4 (DPP4; also called CD26) functions as a cellular receptor for MERS-CoV (4). We and others have recently determined the crystal structure of MERS-CoV RBD bound to the extracellular domain of human DPP4 $(32,33)$. We showed that MERS-CoV RBD consists of a core and a receptor binding subdomain. The receptor binding subdomain directly interacts with blades 4 and 5 of DPP4 propeller but not its intrinsic hydrolase domain $(32,33)$. This finding suggests that agents capable of disrupting such interaction could serve as potential candidates for blocking entry of MERS-CoV into the target cell. Indeed, both polyclonal and monoclonal antibodies (mAbs) directed against DPP4 have been shown to inhibit MERS-CoV infection of primary human bronchial epithelia cells and Huh7 cells $(4,34)$. However, considering the important roles of DPP4 in immune regulation of T cell activation and chemokine function (35), antibodies against DPP4 may potentially lead to unwanted adverse effects when applied to human use. Antibodies directed to the viral receptor binding subdomain would therefore be more favored. Furthermore, RBDbased vaccine studies in experimental animals showed that induced 
Fig. 1. Isolation and sequence analysis of MERS-CoV RBD-specific scFvs from nonimmune human antibody library displayed on the surface of yeast S. cerevisiae. (A) Flow cytometry analysis of sorted yeast population after second MACS (MACS2), first FACS (FACS1), and second FACS (FACS2). (B) Fourteen yeast clones with detectable binding specificity to MERS-CoV RBD. Negative controls include yeast clones either not induced in SG-CAA medium (Negative-1) or induced but no RBD was added to the medium (Negative-2). $\mathrm{Cmyc}$ is a protein tag used for monitoring scFv expression under induction condition. (C) Sequences of complementarity-determining region 3 (CDR3) for both $V_{H}$ and $V_{L}$ of the 14 yeast clones, together with their family designations and degree of similarity compared to their germline sequences.

polyclonal antibodies directed against MERS-CoV RBD can strongly inhibit the entry of MERS-CoV (36-39). These results provide the critical proof of concept that antibody directed against RBD is an effective way of blocking entry of MERS-CoV. Here, we report isolation and characterization of two potent human neutralizing $\mathrm{mAbs}$ against both pseudotyped and live MERS-CoV infection from nonimmune human antibody library. The mechanism of action of these neutralizing mAbs was to block interaction between the RBD on the S glycoprotein of MERS-CoV and cellular receptor DPP4. We believe the neutralizing mAbs identified here hold great promise for the development of prophylactic and therapeutic interventions against MERS-CoV infection.

\section{RESULTS}

\section{Isolation of MERS-CoV RBD-specific single-chain variable region fragments from nonimmune human antibody library}

We used purified and biotin-labeled soluble MERS-CoV RBD as antigen bait to select antibodies from nonimmune human single-chain variable region fragment $(\mathrm{scFv})$ library displayed on the surface of yeast Saccharomyces cerevisiae $(40,41)$. The selection process consisted of two rounds of magnetic bead-activated cell sorting (MACS) followed by additional two rounds of florescence-activated cell sorting (FACS). Increasing proportion of RBD-specific yeast
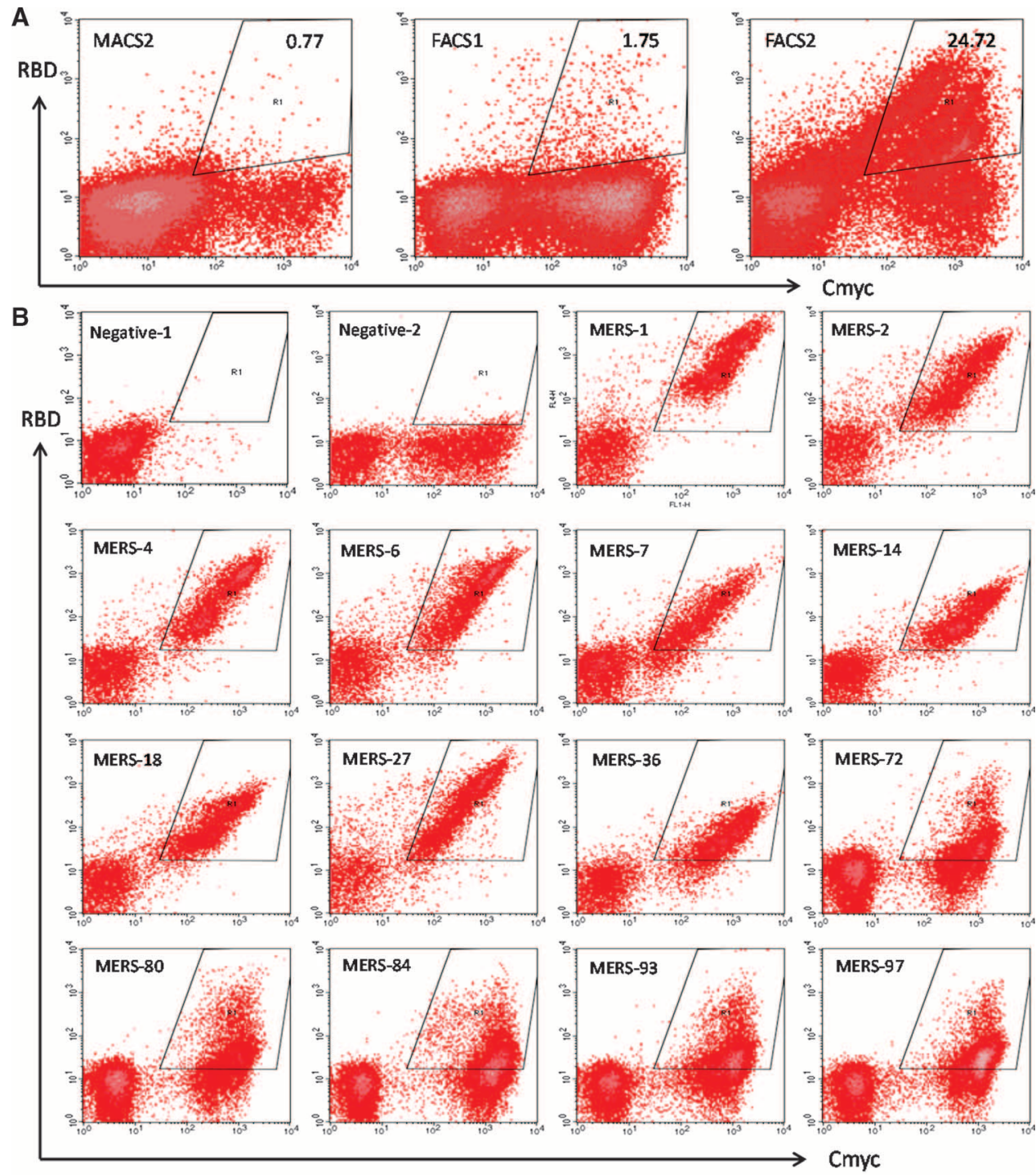

C

\begin{tabular}{|c|c|c|c|c|c|c|c|c|c|c|c|}
\hline \multirow[b]{2}{*}{ ID } & \multicolumn{6}{|c|}{$V_{H}$} & \multicolumn{5}{|c|}{$V_{k / \lambda}$} \\
\hline & $\mathbf{v}$ & D & J & $\begin{array}{l}\text { Identity } \\
(\%)\end{array}$ & $\begin{array}{l}\text { COR3 } \\
\text { (aa) }\end{array}$ & $\begin{array}{l}\text { Length } \\
\text { (aa) }\end{array}$ & v & J & $\begin{array}{l}\text { Identity } \\
\text { (\%) }\end{array}$ & $\begin{array}{l}\text { CDR3 } \\
\text { (aa) }\end{array}$ & $\begin{array}{l}\text { Length } \\
\text { (aa) }\end{array}$ \\
\hline MERS-1 & IGHV4-34*01 & IGHD2-2*01 & IGHJ4:02 & 92.4 & ASHMPFLYAFDYWG & 14 & IGLV1-44*01 & $\mid G U 7^{*} 01$ & 98.3 & AAWDDSLNGPVFG & 13 \\
\hline MERS-2 & IGHV2-5*10 & IGHD3-10*01 & IGHJ3*02 & 94.5 & IGFGEGVGALDIWG & 14 & IGLV3-21*01 & |GU7*01 & 96.4 & QVWDSSSDLGALFG & 14 \\
\hline MERS-4 & IGHV3-30-3*01 & IGHD6-19*01 & IGHJ4*02 & 94.5 & AGNDYWG & 7 & IGLV1-47*01 & |GU7*01 & 98.0 & AAWDDSLSGAVFG & 13 \\
\hline MERS-6 & IGHV6-1*01 & IGHDS-24*01 & IGHJ6*04 & 93.8 & ARDGSPGSSGTYPFFLVWG & 20 & IGLV2-23*03 & |GU7*01 & 92.0 & CSLANNIVFG & 10 \\
\hline MERS-7 & IGHV1-69*04 & IGHD4-23*01 & IGHJ3*02 & 91.2 & ARGVRPRWTHAFDIWG & 14 & IGKV3-20*01 & $1 G K J 2^{*} 02$ & 95.5 & QQYGSSPFTFG & 11 \\
\hline MERS-14 & IGHV1-3*01 & IGHD6-19*01 & IGHJ5*02 & 90.2 & ARDGGKGWHSUWG & 14 & IGKVS-2*01 & $1 G K J 5^{*} 01$ & 99.7 & LOHDNFPLEITFG & 13 \\
\hline MERS-18 & IGHV2-5*09 & IGHD3-10*02 & IGHJ4*02 & 97.0 & AHIIYRSGRDDSWG & 14 & $1 G K V 3-20^{*} 01$ & IGKJ3*01 & 95.8 & QQYGRSRIFTFG & 12 \\
\hline MERS-27 & IGHV3-11*03 & IGHD3-3*01 & IGHJ1*01 & 93.9 & VRDRDDFWSGYYKHWG & 16 & IGKV1D-33*01 & IGKJS*01 & 93.0 & QQYDKLPTFG & 10 \\
\hline MERS-36 & IGHV1-2*02 & IGHD3-22*01 & IGHJ6*02 & 91.9 & ARAGGYHDSNGSTSSYGLWWG & 22 & IGLV1-47*02 & IGU7*01 & 97.2 & AAWDDSLRGAVFG & 13 \\
\hline MERS-72 & IGHV2-5*10 & IGHD3-10*01 & IGHJ3*02 & 94.5 & IGFGEGVGALDIWG & 14 & IGLV3-21*01 & |GU7*01 & 96.1 & HWWDSSSDLGALFG & 14 \\
\hline MERS-80 & 1GHV3-15*02 & IGHDS-24*01 & $1 G H J 2 * 01$ & 92.4 & TTEDRKDGYRVFDLWG & 16 & IGKV3-20*01 & IGKJ1*01 & 95.1 & QLFGSSTETFG & 11 \\
\hline MERS-84 & IGHV3-30*18 & IGHDS-5*01 & IGHJ6*02 & 94.6 & VKDDGYSYGYKYYYGMDVWG & 20 & IGKV3-20*01 & IGKJ3*01 & 98.6 & QQYGSSPSFG & 10 \\
\hline MERS-93 & IGHV2-5*09 & IGHD3-22*01 & IGHJ3*01 & 94.7 & AHRRRGGDYYOSNGYYWG & 18 & IGKVS-2*01 & IGKJ3*01 & 99.7 & LQHDNFPUFTFG & 12 \\
\hline MERS-97 & IGHV2-5*09 & IGHD3-10*01 & IGHJ3*02 & 97.3 & IGFGEGVGALIWG & 14 & & & $\mathbf{N}$ & & \\
\hline
\end{tabular}


population was observed from $0.77 \%$ after the second MACS, to $1.75 \%$ after the first FACS, and up to $24.72 \%$ after the second FACS (Fig. 1A). Plasmid DNA containing the coding sequences for scFv was extracted from the yeast population sorted by the second FACS and then transformed into Escherichia coli for the production of sufficient quantity for sequencing and sequence analysis. Among the total 120 plasmid sequences analyzed, 23 distinct $s c F v$ sequences were identified and 14 of which were confirmed specifically binding to MERS-CoV RBD once transformed back and expressed on the surface of the yeast (Fig. 1B). Each of the $14 \mathrm{scFvs}$ had distinct $\mathrm{V}_{\mathrm{H}}$ and $\mathrm{V}_{\mathrm{L}}$ sequences (fig. S1). Some of the scFvs, however, share identical CDR3 sequences in $\mathrm{V}_{\mathrm{H}}$ such as MERS-2, MERS-72, and MERS-97 (Fig. 1C). One clone (MERS-97) completely lacked a $V_{L}$. The gene families of the $14 \mathrm{scFvs}$ were quite divergent for both $\mathrm{V}_{\mathrm{H}}\left(3 \mathrm{~V}_{\mathrm{H}} 1,6 \mathrm{~V}_{\mathrm{H}} 2\right.$, $4 \mathrm{~V}_{\mathrm{H}} 3,1 \mathrm{~V}_{\mathrm{H}} 4$, and $\left.1 \mathrm{~V}_{\mathrm{H}} 6\right)$ and $\mathrm{V}_{\mathrm{L}}\left(3 \mathrm{~V}_{\lambda} 1,1 \mathrm{~V}_{\lambda} 2,2 \mathrm{~V}_{\lambda} 3,1 \mathrm{~V}_{\kappa} 1,5 \mathrm{~V}_{\kappa} 3\right.$, and $2 \mathrm{~V}_{\mathrm{\kappa}} 3$ ) (Fig. 1C).

\section{Neutralizing activity of human immunoglobulin G1 form of selected scFv against pseudotyped and live MERS-CoV infection}

To evaluate neutralizing activity of selected 14 scFvs, we generated bivalent full-length human mAbs by fusing the variable region of each $\mathrm{scFv}$ with the constant region fragment of human immunoglobulin G1 (IgG1). Once confirmed by sequencing, 14 pairs of full-length heavy and light chain plasmids were cotransfected into $293 \mathrm{~T}$ cells for the production and purification of mAbs. Neutralizing activity of these mAbs was then tested on susceptible Huh7 cells against pseudovirus infection expressing the MERS-CoV S glycoprotein. As shown in Fig. 2A, two mAbs (MERS-4 and MERS-27) demonstrated neutralizing activities with $\mathrm{IC}_{50}$ (half-maximal inhibitory concentration) less than $100 \mathrm{nM}$; MERS-4 was 0.37 nM, whereas MERS-27 was 63.96 nM. Furthermore, neutralizing activities of these two mAbs were specific against MERS-CoV because none of the pseudovirus bearing the envelope glycoprotein of SARS-CoV, HIV-1, or VSV-G was susceptible to their neutralization (Fig. 2A). Neutralizing activities of these two mAbs against live MERS-CoV were also studied using the clinical isolate hCoV-EMC from a MERS-CoV-infected patient (6). As shown in Fig. 2B, both MERS-4 and MERS-27 demonstrated potent inhibitory activity against MERS-CoV infection, with $\mathrm{IC}_{50}$ of 3.33 and $13.33 \mathrm{nM}$, respectively. Such inhibitory activities were comparable to that against pseudotyped MERS-CoV, although clear variations existed between the live and pseudotyped systems. In both systems, however, MERS-4 showed more potent neutralizing activity than MERS-27. In addition, we evaluated inhibitory activities of these two mAbs on syncytia formation between cells expressing the MERS-CoV S glycoprotein and those expressing the receptor DPP4. Specifically, the monkey kidney fibroblast cell line COS7 was transfected with plasmids encoding either full-length MERS-CoV S protein or human receptor DPP4. Twentyfour hours after transfection, transfected cells were trypsinized, washed, and mixed at a 1:1 ratio in the presence of $100 \mu \mathrm{g} / \mathrm{ml}$ of each of the two mAbs. Syncytia formation was observed under the microscope 36 hours afterward. Consistent with the neutralization results, MERS-4 was the most potent and completely inhibited syncytia formation at the indicated concentration, whereas MERS-27 was relatively inefficient (Fig. 2C). These results suggested that both MERS-4 and MERS-27 are potent inhibitors against MERS-CoV, and the potential reasons for their differences in inhibitory capacity are explained and discussed below.
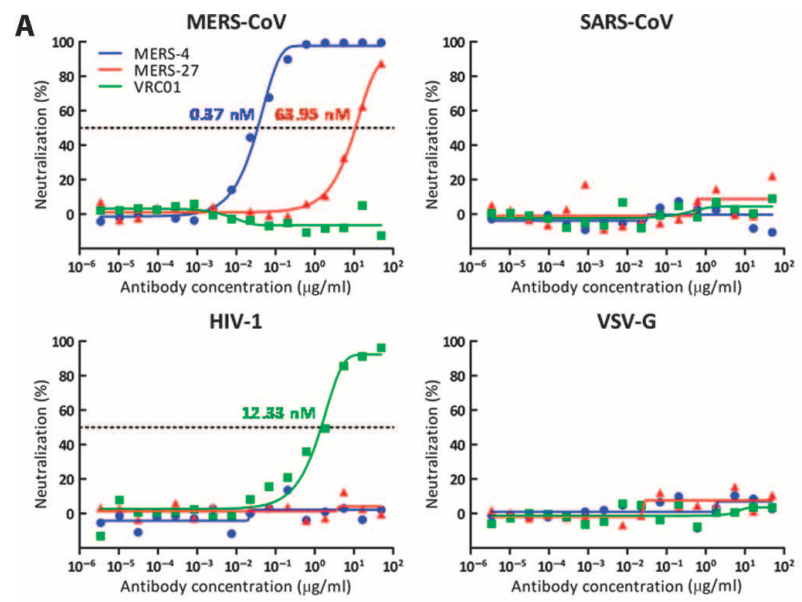

B

Live MERS-CoV

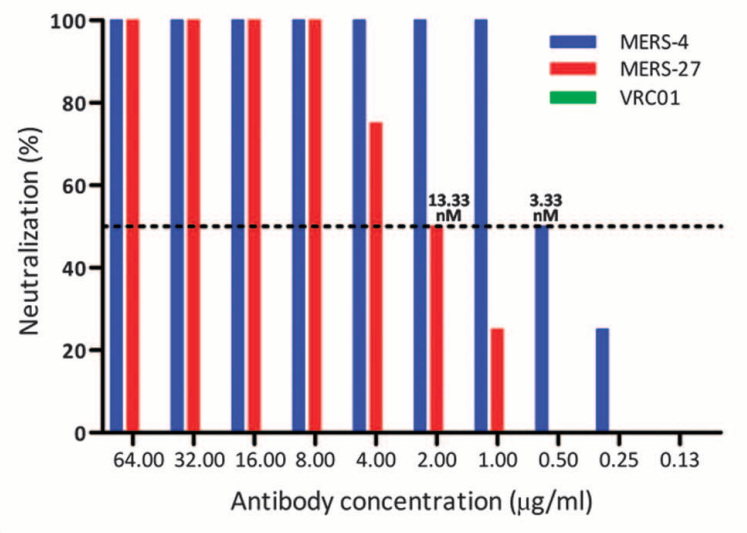

C
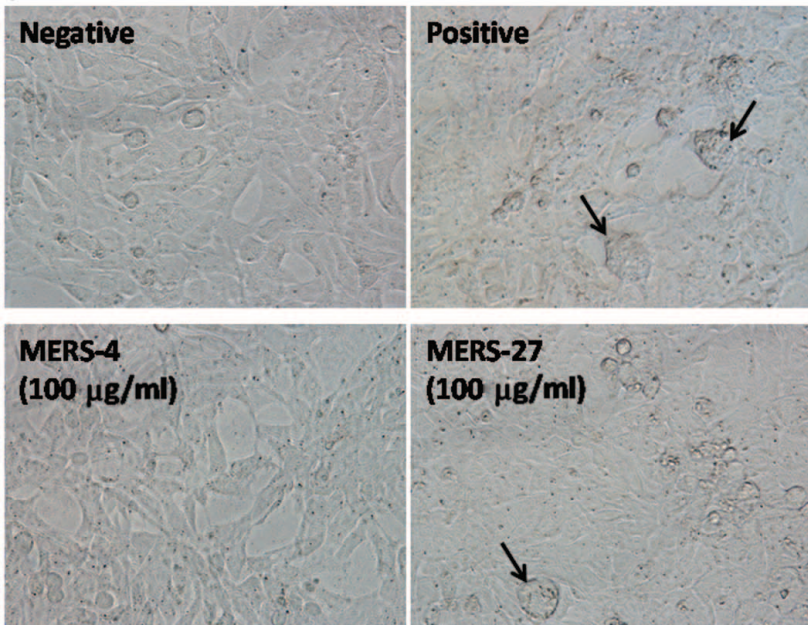

Fig. 2. Neutralizing activities of MERS-4 and MERS-27 against pseudotyped (A) and live (B) MERS-CoV, and against syncytia formation of COS7 cells mediated by the MERS-CoV S glycoprotein and the receptor DPP4 (C). Pseudoviruses bearing the envelope glycoprotein from SARS-CoV, HIV-1, or VSV-G were used as controls. Data shown are average values from four (A) and two (B) independent experiments. Dashed line indicates 50\% inhibition, and two numbers (13.33 and $3.33 \mathrm{nM}$ ) above it are the $\mathrm{IC}_{50}$ s for MERS-27 and MERS-4, respectively. VRC01 is a human neutralizing mAb against HIV-1 and used as a control. In (C), negative control represents COS7 cells transfected with mouse DPP4, whereas positive control represents those transfected with human DPP4 expression vector. 
Blocking of RBD binding to receptor DPP4 by neutralizing mAbs Because all $\mathrm{mAbs}$ reported here were initially isolated on the basis of their recognition of RBD, observed neutralizing activity of MERS-4 and MERS-27 might be mediated through their competitive binding to RBD, thereby interfering or disrupting interaction between RBD and cellular receptor DPP4. To test this hypothesis, we first examined whether the two mAbs could inhibit the binding of soluble RBD to DPP4-expressing susceptible Huh7 cells. As shown in Fig. 3A, when Huh7 cells were incubated with soluble RBD in the presence of varying concentrations of the two mAbs and analyzed by flow cytometry, differential inhibitory effects were observed. Consistent with the neutralization results against live and pseudotyped MERS-CoV and inhibitory effect on syncytia formation, MERS-4 was more potent than MERS-27 in inhibiting interaction between soluble RBD and receptor DPP4 on the surface of Huh7 (Fig. 3A). At a concentration of 333 $\mathrm{nM}$ (about two times greater molar concentration than soluble RBD), MERS-4 completely blocked the binding of soluble RBD to Huh7 cells, and clear dose effect was also identified (Fig. 3A, left). In contrast, MERS-27 demonstrated relatively modest inhibitory activity under the same experimental conditions (Fig. 3A, right). Second, we studied whether the binding kinetics and affinities of the two

A
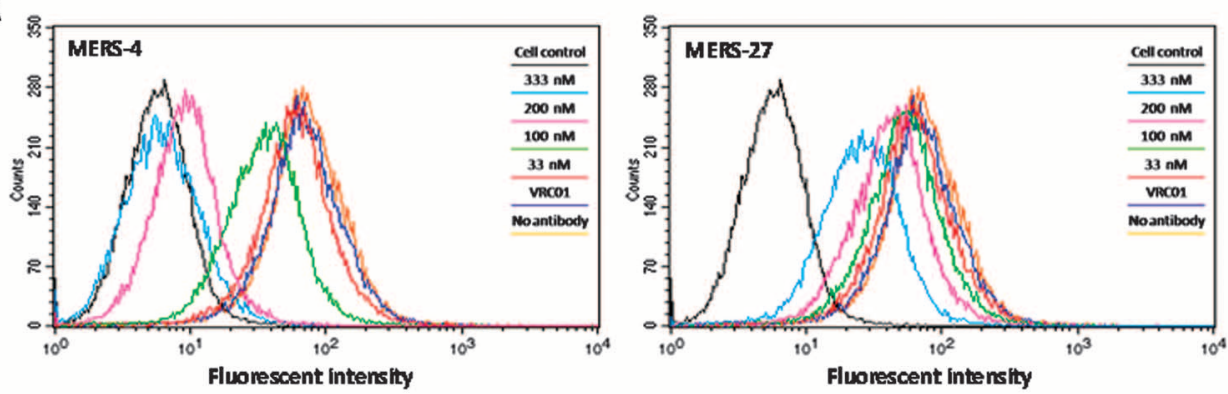

B
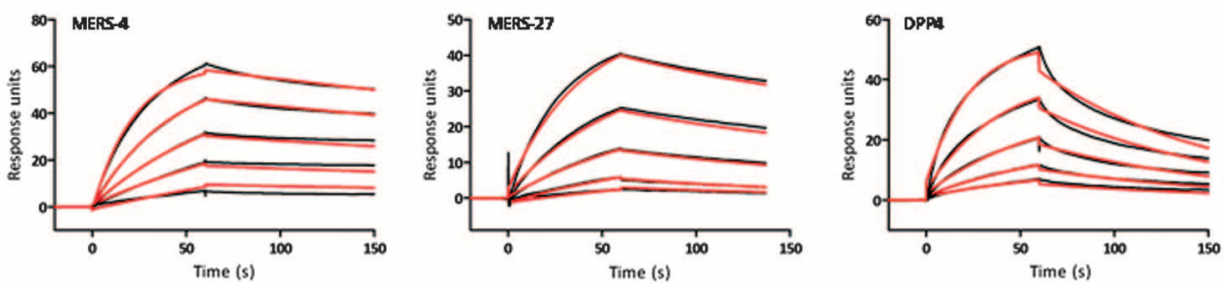

C

\begin{tabular}{lcccc} 
Analyte & $K_{\text {on }}\left(\mathrm{M}^{-1} \mathrm{~s}^{-1}\right)$ & $K_{\text {off }}\left(5^{-1}\right)$ & $K_{\mathrm{a}}\left(\mathrm{M}^{-1}\right)$ & $K_{\mathrm{d}}(\mathrm{M})$ \\
\hline DPP4 & $2.75 \mathrm{E}+05$ & $1.17 \mathrm{E}-02$ & $2.24 \mathrm{E}+07$ & $4.45 \mathrm{E}-08$ \\
MERS-4 & $1.47 \mathrm{E}+05$ & $1.44 \mathrm{E}-03$ & $1.02 \mathrm{E}+09$ & $9.78 \mathrm{E}-10$ \\
MERS-27 & $1.02 \mathrm{E}+05$ & $7.28 \mathrm{E}-03$ & $1.40 \mathrm{E}+07$ & $7.12 \mathrm{E}-08$ \\
\hline
\end{tabular}

Fig. 3. MERS-4 and MERS-27 blocked the interaction between soluble RBD and receptor DPP4 on the Huh7 cell surface (A) and their binding kinetics and affinity to RBD (B and C). Flow cytometry analysis of soluble RBD binding to receptor DPP4 in the presence of varying concentrations of MERS-4 (A, left) or MERS-27 (A, right). VRC01 is a human neutralizing mAb against HIV-1 and used as a control. Overlay of binding of varying concentrations of MERS-4 and MERS-27 to RBD immobilized on the CM5 sensor chip (B). The black lines indicate the experimentally derived curves, whereas the red lines represent fitted curves based on the experimental data. $K_{\text {on }}$ (association rate, in $\mathrm{M}^{-1} \mathrm{~s}^{-1}$ ), $K_{\text {off }}$ (dissociation rate, in $\mathrm{s}^{-1}$ ), $K_{\mathrm{a}}$ (association constant, in $\mathrm{M}^{-1}$ ), and $K_{\mathrm{d}}$ (dissociation constant, in $\mathrm{M}$ ) are indicated for each paired interaction (C).
mAbs to RBD measured by surface plasmon resonance (SPR) are associated with their neutralizing activities. As shown in Fig. 3 (B and C), MERS-4 had about 45 -fold higher binding affinity $\left(K_{\mathrm{d}}=\right.$ $98 \mathrm{nM})$ to RBD than soluble DPP4 $\left(K_{\mathrm{d}}=44.5 \mathrm{nM}\right)$. MERS-27, how, shared comparable binding affinity $\left(K_{\mathrm{d}}=71.2 \mathrm{nM}\right)$ to RBD with the two, perhaps due to

\section{Cooperativity of the two neutralizing mAbs for virus neutralization}

Because both MERS-4 and MERS-27 blocked binding of RBD to cellular receptor DPP4, we went further to determine whether the combination of (t) $\mathrm{IC}_{50}$ concentrations as determined above in Fig. 2A. Dose-dependent neutralization activity for MERS-4, MERS-27, or the combination thereof was then evaluated by serial threefold dilutions in concentrations from 27 times the $\mathrm{IC}_{50}$ to $1 / 81$ of the $\mathrm{IC}_{50}$. Figure 4 shows the average results from four independent experiments to determine percent neutralization (Fig. 4A), fractional effect (Fig. 4B), and the combination index (CI) (Fig. 4C) using the CompuSyn program. Percent neutralization for combined MERS-4 and MERS-27 was about 5.26-fold reduction in $\mathrm{IC}_{50}$ and 4.89-fold reduction in $\mathrm{IC}_{90} \mathrm{com}$ pared to that for MERS-4 or MERS-27 alone (Fig. 4A). Furthermore, the CI values of combined MERS-4 and MERS-27 at fractional effect values of effective dose 25 , 50, 75, 90, and $95 \%\left(\mathrm{ED}_{25}, \mathrm{ED}_{50}, \mathrm{ED}_{75}, \mathrm{ED}_{90}\right.$, and $\mathrm{ED}_{95}$ ) were $0.22,0.28,0.34,0.42$, and 0.50 , respectively. As a CI value of 1 indicates an additive effect, $<1$ indicates synergism, and $>1$ indicates antagonism, the combined MERS-4 and MERS-7 are clearly in strong synergism (0.1 to 0.3$)$ at $\mathrm{ED}_{25}$ and $\mathrm{ED}_{50}$ and synergism (0.3 to 0.7$)$ at $\mathrm{ED}_{75}, \mathrm{ED}_{90}$, and $\mathrm{ED}_{95}(42,43)$. Figure $4 \mathrm{C}$ shows a logarithmic $\mathrm{CI}$ scale, values greater than 0 are indicative of antagonism, and values less than 0 are indicative of synergism. Similarly, combination of MERS-4 and MERS-27 demonstrated strong synergistic effect at lower antibody concentration and modest degree of synergism at higher antibody concentration, perhaps due to certain degree of steric hindrance in the binding of these two antibodies when they were in higher abundance.

\section{Epitope mapping of MERS-4 and MERS-27}

Because MERS-4 and MERS-27 appeared to be synergistic in neutralizing activity, 
epitopes recognized by the two mAbs were likely to be different. To test this hypothesis, we generated a total of 14 mutant MERS-CoV S glycoproteins with single- or multiple-residue substitutions at the interface between RBD and DPP4 (Fig. 5A). All but two (13 and 14) pseudotyped viruses bearing the mutant $S$ glycoprotein were able to infect Huh7 cells and therefore used to test for their relative resistance to MERS-4 and MERS-27 neutralization and compared to those bearing the wild-type S glycoprotein. As shown in Fig. 5 (A and B), several mutations resulted in substantial increases in resistance against neutralization of MERS-4. For instance, a single-residue substitution of D455A, E513A, and R542A increased resistant levels about 6-, 13-, and 3-fold against MERS-4, respectively, whereas the same mutation had little impact on resistance to MERS-27. Some residue substitutions such as Y499A, R511A, and, in particular, W553A increased sensitivity of MERS-CoV to MERS- 4 and MERS-27 neutralization, presumably by affecting RBD structure in such a way allowing anti- body easier to access and bind with higher affinity. Lastly, because none of the mutations had significantly increased resistance to MERS-27, its epitope or major residues recognized were likely located beyond the residues studied here. These findings suggest that the epitopes recognized by MERS- 4 and MERS-27 are rather distinct, which is consistent with the coaction between the two mAbs in neutralizing activity against pseudotyped MERS-CoV.

To understand the spatial relationship of the abovementioned residues and their differences in conferring resistance to MERS-4 and MERS-27, we highlighted their positions on the crystal structure of RBD previously resolved by our group (33). As shown in Fig. 5C, critical residues conferring resistance to MERS-4 (D455A, E513A, and R542A) constitute a wide triangle area (red) located right at the center of the interface between RBD and receptor DPP4. If the red triangle could indeed represent the footprint of MERS- 4 on the RBD, it may help to explain why MERS-4 is such a potent mAb capable of inhibiting live and
A

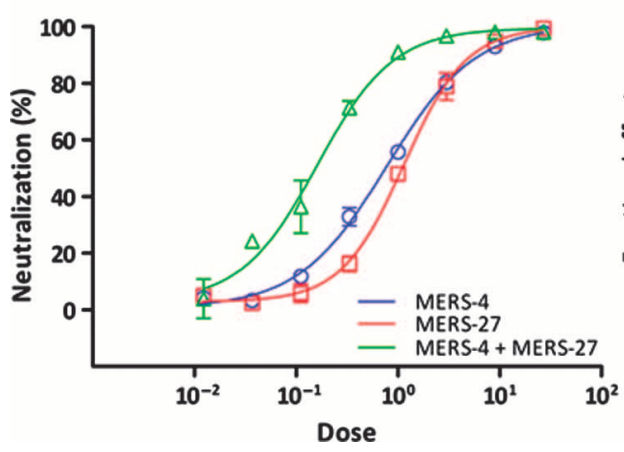

B

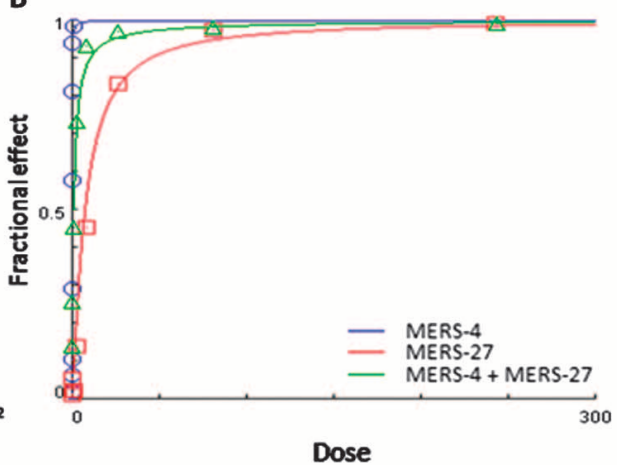

C

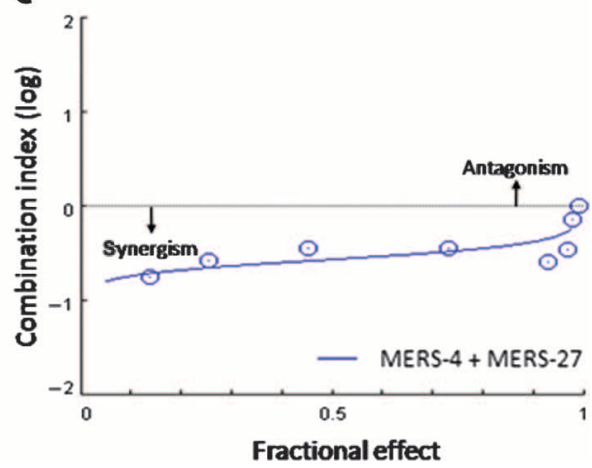

Fig. 4. Effects of combined MERS-4 and MERS-27 in neutralizing pseudotyped MERS-CoV. (A) Percent neutralization was calculated for serial threefold dilutions of each antibody alone and in combination at constant ratios in a range of concentrations from 27 times to $1 / 81$ of $\mathrm{IC}_{50} \mathrm{~s}$. The constant ratios of the combined antibodies were their $I_{50}$ s. On the $x$ axis, a dose of 1 was at the $I C_{50}$ con-

centration. (B) Fractional effect (FA) plots generated by the CompuSyn program for MERS-4, MERS-27, and their combination showing dosage versus effect. (C) Median effect plot of calculated $\mathrm{Cl}$ values (logarithmic) versus FA values, in which a $\log \mathrm{Cl}$ of $<0$ is synergism and a $\log \mathrm{Cl}$ of $>0$ is antagonism. Data shown are average values from four independent experiments.

A

\begin{tabular}{cccc} 
A & & \multicolumn{2}{c}{$\begin{array}{c}\text { Fold increase in K } \\
\text { relative to wild-type }\end{array}$} \\
\cline { 3 - 4 } $\begin{array}{c}\text { Mutant } \\
\text { viruses }\end{array}$ & $\begin{array}{c}\text { Residue } \\
\text { mutation }\end{array}$ & MERS-4 & MERS-27 \\
\hline 1 & D455A & 6.02 & 1.26 \\
2 & P463A & 1.58 & 0.91 \\
3 & Y499A & 0.95 & 0.72 \\
4 & L506A & 2.71 & 0.78 \\
5 & D510A & 1.65 & 0.79 \\
6 & R511A & 094 & 0.18 \\
7 & E513A & 13.18 & 1.35 \\
8 & Y540F & 1.54 & 0.60 \\
9 & R542A & 3.16 & 0.49 \\
10 & W553A & 0.08 & 0.17 \\
11 & V555A & 1.02 & 0.70 \\
12 & S55N & 1.05 & 1.51 \\
13 & L5OSAMN53AN555A & NA & NA \\
14 & E536R/D537K/D539K & NA & NA \\
\hline & & &
\end{tabular}

B

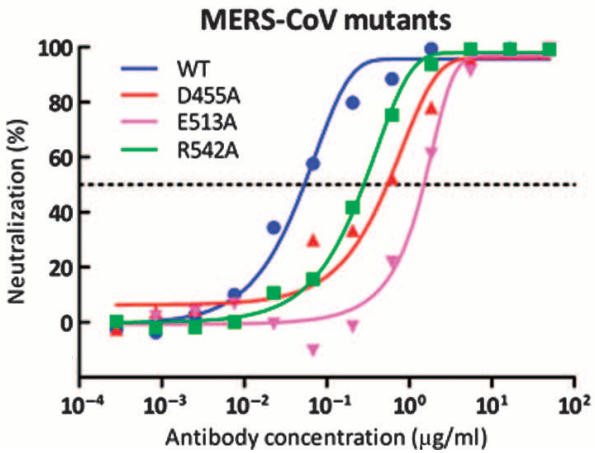

C

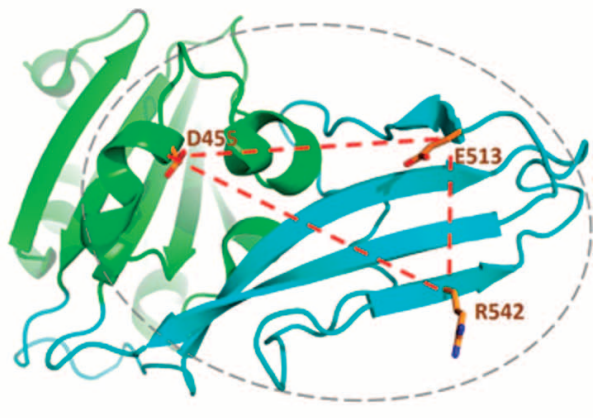

Fig. 5. Epitope mapping of MERS-4 and MERS-27 by mutagenesis ( $A$ and $B$ ) and spatial analysis of the key residues on the crystal structure of RBD (C). The residue substitutions and their locations on the RBD are indicated (A). Numbers in the column under MERS-4 and MERS-27 represent the fold changes in $\mathrm{IC}_{50}$ of mutant viruses relative to the wildtype (WT) ( $>1$ : increase resistance and $<1$ : increase sensitivity). Identified key residues in conferring resistance to MERS-4 are highlighted in red (A) as well as on the crystal structure of RBD (C). The core and receptor binding subdomains of RBD are colored with green and cyan, respectively. Red triangle indicates the potential binding area of MERS-4 containing residues D455, E513, and R542, whose mutations increased resistance to MERS-4. 
pseudotyped MERS-CoV as well as syncytia formation. Furthermore, because none of the abovementioned residues had significantly increased the resistance to MERS-27, the epitope of MERS-27 may likely be located away from that recognized by MERS- 4 .

\section{DISCUSSION}

MERS-CoV is a newly identified coronavirus that causes severe and fatal acute respiratory illness in humans $(3,5,6,21,45)$. Although the direct reservoir remains uncertain, the existence of MERS-CoV in several animal species allows further zoonotic transmission and introduction to humans $(5,9,12,13,15,17)$. Despite no current evidence of sustained human-to-human transmission, MERS-CoV may evolve to spread quickly among humans and affect wider geographic areas. Clearly, there is an urgent need for an effective antiviral therapy and vaccines for this emerging global threat. This study aimed to identify human mAbs capable of inhibiting MERS-CoV infection through disrupting interaction between envelope $S$ glycoprotein of MERS-CoV and its cellular receptor DPP4. Specifically, the RBD on the envelope S glycoprotein served as an ideal target because entry of MERS-CoV is dependent on its interaction with DPP4 $(4,32,33)$. Extended from our previous anatomic understanding of interaction between RBD and DPP4 (33), we used highly purified and structurally intact soluble $\mathrm{RBD}$ as bait to select antibodies from nonimmune human scFv library. Two mAbs (MERS-4 and MERS-27) with potent neutralizing activities against MERS-CoV infection were successfully isolated. Both of the two mAbs were able to inhibit infection of pseudotyped and live MERS$\mathrm{CoV}$ with $\mathrm{IC}_{50}$ at nanomolar concentration, although MERS-4 demonstrated more potency than MERS-27. MERS-4 also showed inhibitory activity against syncytia formation mediated by envelope and receptorexpressing cells. In addition, synergistic effect was also found when MERS-4 and MERS-27 were used in combination for neutralization against pseudotyped MERS-CoV, providing a rationale for the combined use in future animal and clinical testing. Biochemical analysis indicated that the mechanism of action of the two mAbs was to block interaction between RBD and cellular receptor DPP4. MERS-4, in particular, bound soluble RBD with an about 45-fold higher affinity than DPP4. Mutagenesis analysis suggested that MERS-4 and MERS-27 recognized distinct regions in RBD, but more work would be required for the fine mapping of epitopes in the future. Collectively, these results suggest that MERS-4 and MERS-27 are RBD-specific potent inhibitors and could serve as promising candidates for prophylactic and therapeutic interventions against MERS-CoV infection.

Because neutralizing antibodies can protect hosts from viral infection, attenuate disease progression, and alleviate clinical symptoms in other viral infections (46), it is reasonable to believe that antibodies identified here hold great potential and promise for the development of prophylactic and therapeutic interventions against MERS-CoV infection. In particular, the combined effect of the two mAbs would be expected to provide stronger and broader neutralizing activity against wild-type or mutant MERS-CoVs should mutations occur during viral infection and transmission. Although the current data set for RBD that interfaces with DPP4 shows limited degree of sequence variation (fig. S2), this is by no means to suggest RBD will remain unchanged in the long run considering wide spread of MERS-CoV in several animal species and continuing zoonotic introductions into human populations $(3-6,9-17,21,45,47)$. In this regard, clear understanding of the epitope recognized by the two mAbs would be important to assess their potential to inhibit the current and future variants of MERS-CoV. This could be achieved through additional site-directed mutagenesis and/or crystal structural analysis of RBD-antibody complexes. Furthermore, because the two mAbs were isolated from the artificial scFvs of nonimmune human antibody library, they may bear some nonspecific recognition against host antigens. To this end, we tested their potential polyreactivity by antinuclear antibody test, anti-dsDNA (double-stranded DNA) test, and anti-extractable nuclear antigen profile and found no such reactivity was detectable at a concentration of $100 \mu \mathrm{g} / \mathrm{ml}$ (fig. S3). Testing pharmacokinetics, safety, and efficacy of these mAbs in appropriate animal models and clinical trials will demonstrate their potential use as potent entry inhibitors for emergency prophylaxis and treatment of MERS.

\section{MATERIALS AND METHODS}

\section{Study design}

This study was designed to isolate human mAbs capable of inhibiting MERS-CoV infection through disrupting interaction between envelope S glycoprotein of MERS-CoV and its cellular receptor DPP4. More specifically, the RBD on the envelope $S$ glycoprotein served as an ideal target because entry of MERS-CoV is dependent on its interaction with DPP4. To this end, we used highly purified and structurally intact soluble RBD as bait to select antibodies from nonimmune human scFv library displayed on the surface of the yeast $S$. cerevisiae. Although other types of antibody library exist, we chose yeast surfacebased antibody library and selection largely due to its ease of use. The staining, detection, and sorting of antigen-antibody complexes were conducted in solution that most likely reflected the intrinsic interaction between antigen and antibody within the host. This feature would minimize the confounding nonspecific interaction of antibodies with solid surface-bound antigens used in enzyme-linked immunosorbent assay, biopanning in phage display, or other systems. Once the yeast clones expressing specific scFvs were found to bind to soluble RBD, a complete form of antibody was constructed in the backbone of IgG1. Neutralizing activity of the complete antibodies was then tested against both pseudotyped and live MERS-CoV. Their inhibitory activity against cell-to-cell fusion was also evaluated. Biochemical and site-directed mutagenesis studies were then performed to understand mechanism of action, interaction when used in combination, and polyreactivity against host antigens and to identify their epitope recognized. For each assay, at least four replicates were conducted with the same experimental conditions, and at least two independent experiments were performed for each assay. All these characterizations will provide critical references for future development of isolated antibodies in animal and clinical use.

\section{Expression, purification, and biotinylation of MERS-CoV RBD} The MERS-CoV RBD (residues 367 to 588 on S1 glycoprotein) was fused at the $\mathrm{C}$ terminus with a 15-residue (GLNDIFEAQKIEWHE) biotinylation tag (AviTag) and a His-6 tag. The whole sequence was cloned into the pFastBac Dual vector (Invitrogen), which was then transformed into bacterial DH10Bac component cells to generate recombinant baculovirus plasmid (bacmid). Transfection of recombinant bacmid DNA into Sf9 insect cells led to the generation of recombinant baculovirus particles, which was then amplified and used to infect 2 liters of Sf9 cells at a 
density of $2 \times 10^{6}$ cells $/ \mathrm{ml}$. The supernatant of cell culture was harvested 72 hours after infection, and recombinant MERS-CoV RBD was subsequently purified by Ni-NTA affinity column and HiLoad Superdex 75 gel filtration column (GE Healthcare). For biotinylation, the purified MERS-CoV RBD was concentrated to $40 \mu \mathrm{M}$ and then incubated with biotin ligase (BirA) in the presence of biotin and adenosine triphosphate. This allowed covalent linkage of biotin to the lysine residue in the AviTag motif (one per monomer), distal to the MERS-CoV RBD antigenic surface.

\section{Selection of yeast library for MERS-CoV RBD-specific ScFvs} Human nonimmune scFv library $\left(\sim 1 \times 10^{9}\right)$ constructed from the spleen and lymph node polyadenylated RNA pooled from 58 normal humans was provided by C. Baird (Pacific Northwest National Laboratory) (41). Purified and biotinylated soluble MERS-CoV RBD was used as bait to select $2 \times 10^{9}$ yeast cells by two rounds of MACS followed by additional two rounds of FACS with a BD FACSAria II sorter. Between each round of selection, the sorted yeast cells were grown in SD-CAA and induced in SG-CAA medium as previously reported (40). After the second FACS, the sorted yeast population was subjected to DNA plasmid extraction, which was then transformed into E. coli DH5 $\alpha$ for producing sufficient amount of DNA for sequencing and sequence analysis. The DNA plasmids containing the distinct $\mathrm{scFv}$ sequences were then transfected back to yeast to identify their binding specificity to MERSCoV RBD.

\section{Expression and purification of MERS-CoV RBD-specific whole-human IgG1 mAbs}

The heavy and light chain genes of MERS-CoV RBD-specific scFvs were separately cloned into backbone of antibody expression vectors containing the constant regions of IgG1, which was provided by M. C. Nussenzweig (Rockefeller University). Whole-human IgG1 was expressed in 293T cells by transient transfection, purified by affinity chromatography using protein A agarose, and titered by BCA Protein Assay Kit (Thermo Scientific).

MERS-CoV pseudovirus production and neutralization assay The MERS-CoV pseudovirus was generated as described previously (33). Briefly, pcDNA 3.1 expression vectors encoding the wild-type or mutant MERS-CoV S glycoprotein were cotransfected with a pNL4-3R-Eluciferase viral backbone plasmid into 293T cells. Supernatants containing the pseudovirus were collected 48 hours after transfection, and viral titers were measured in luciferase activity in relative light units (BrightGlo Luciferase Assay System, Promega Biosciences). The mutant S glycoprotein expression vector was generated by the site-directed mutagenesis on the basis of the pcDNA 3.1 expression vector encoding the S glycoprotein (Invitrogen). All mutant clones were confirmed by sequencing. Neutralization assays were performed by incubating $100 \mathrm{TCID}_{50}$ (median tissue culture infectious dose) of pseudovirus with 16 serial 1:3 dilutions of purified antibody at $37^{\circ} \mathrm{C}$ for 1 hour. Huh7 cells (about $1.5 \times$ $10^{4}$ per well) were then added to each antibody and virus mixture. Infectivity was quantified by the luciferase activity 48 hours after infection. $\mathrm{IC}_{50} \mathrm{~s}$ were calculated using the dose-response inhibition model in GraphPad Prism (GraphPad Software Inc.).

\section{Neutralization activity of mAbs against live MERS-CoV}

A clinical isolate of MERS-CoV (hCoV-EMC) was provided by Fouchier and colleagues (6). The isolate was amplified in FRhK-4 to make working stocks of the virus $\left(1 \times 10^{7} \mathrm{TCID}_{50} / \mathrm{ml}\right)$. All experimental protocols involving live MERS-CoV strain hCoV-EMC followed the standard operating procedures of the approved Biosafety Level-3 facility as we previously described (48). Neutralizing titers of mAbs were detected in Vero E6 cells as previously described (49). Briefly, Vero E6 cells were seeded at $10^{4}$ per well in 96 -well culture plates and cultured at $37^{\circ} \mathrm{C}$ to form a monolayer. Serial fourfold dilutions of $\mathrm{mAbs}$ were mixed separately with $100 \mathrm{TCID}_{50}$ of MERS-CoV strain hCoV-EMC, incubated at $37^{\circ} \mathrm{C}$ for 1 hour, and added to the monolayer of Vero E6 cells in tetrad. An unrelated $\mathrm{mAb}$ VRC01 was included as negative control. Cells infected with $100 \mathrm{TCID}_{50}$ MERS-CoV and without the virus were applied as positive and uninfected controls, respectively. Cytopathic effect (CPE) in each well was observed daily and recorded on day 3 after infection. The neutralizing titers of mAbs that completely prevented CPE in $50 \%$ of the wells were calculated by the Reed-Muench method.

\section{Syncytia inhibition assay with neutralizing mAbs}

Monkey kidney fibroblast cell line COS7 was transfected with plasmids encoding the full-length MERS-CoV S glycoprotein or receptor DPP4. One day after transfection, cells were trypsinized and washed once in fresh medium. Those $\mathrm{S}$ protein-expressing cells were premixed with testing $\mathrm{mAbs}$ at the final concentration of $100 \mu \mathrm{g} / \mathrm{ml}$ for $30 \mathrm{~min}$ at $37^{\circ} \mathrm{C}$. These cells were then mixed with cells expressing either human or mouse DPP4 at a 1:1 ratio and plated on 24-well plates. Cells were cultured in the presence of antibodies for additional 36 hours before syncytia was monitored under the light microscope, and representative photographs were taken.

\section{Affinity measurement by Biacore}

The binding kinetics and affinity of neutralizing antibodies and receptor DPP4 to the purified RBD were analyzed by SPR (Biacore T200, GE Healthcare). The purified soluble RBD was covalently immobilized to a CM5 sensor chip via amine group with the Amine Coupling Kit (Biacore) in $10 \mathrm{mM}$ sodium acetate buffer (pH 5.0). Experiments were run at a flow rate of $30 \mu \mathrm{l} / \mathrm{min}$ in HBS buffer. The surface was regenerated with $10 \mathrm{mM} \mathrm{NaOH}$. Sensograms were fit with a 1:1 binding model with BIA Evaluation software (GE Healthcare).

\section{Flow cytometry analysis of inhibition of RBD binding to Huh7 cells by mAbs}

Varying concentrations of testing mAbs were mixed with purified and biotinylated soluble RBD in $100 \mu$ l of phosphate-buffered saline (PBS) and incubated at $4^{\circ} \mathrm{C}$ for 1 hour. Each mixture was then added to Huh7 cells and incubated at $4^{\circ} \mathrm{C}$ for another 1 hour. VRC01, a human $\mathrm{mAb}$ against HIV-1, was used as a negative control. For detection of biotinylated RBD binding to Huh7, cells were washed three times with $500 \mu \mathrm{l}$ of PBS and incubated with phycoerythrin-labeled anti-biotin secondary antibody (eBioscience) at $4^{\circ} \mathrm{C}$ for 30 to $40 \mathrm{~min}$. Cell samples were analyzed with FACSCalibur and FACSComp software (BD Biosciences).

\section{Cooperativity of the two neutralizing mAbs for virus neutralization}

Synergistic, additive, and antagonistic interplay between MERS-4 and MERS-27 for virus neutralization was evaluated by the median effect analysis method with the CompuSyn software (ComboSyn Inc.). This approach, initially described by Chou and Talalay $(42,43)$, determines the dose-dependent neutralization curve of each antibody alone and in combination, at a constant ratio, to calculate a CI. The constant ratio 
of the combined antibodies was set by the $\mathrm{IC}_{50} \mathrm{~s}$ of the MERS- 4 and MERS-27. Neutralization values of serial threefold dilutions of each antibody alone and in combination were then measured in a range of concentrations from 27 times to $1 / 81$ of $\mathrm{IC}_{50}$ s. The measured neutralization values were entered into the program as fractional effects (FA) in the range of $0.01<\mathrm{FA}<0.99$ for each of the two antibodies and for both in combination. The software calculated the $\mathrm{CI}$ values in relation to $\mathrm{FA}$ values. A CI value of 1 indicates an additive effect, $<1$ indicates synergism, and $>1$ indicates antagonism. On a logarithmic CI scale, values greater than 0 are indicative of antagonism, and values less than 0 are indicative of synergism.

\section{Statistical analyses}

For each antibody, $\mathrm{IC}_{50}$ s were calculated using the dose-response inhibition model in GraphPad Prism (GraphPad Software). Synergistic, additive, and antagonistic interplay between antibodies for virus neutralization was evaluated by the median effect analysis method with the CompuSyn software (ComboSyn Inc.). In live MERS-CoV assay, the neutralizing titers of mAbs that completely prevented CPE in 50\% of the wells were calculated by the Reed-Muench method.

\section{SUPPLEMENTARY MATERIALS}

www.sciencetranslationalmedicine.org/cgi/content/full/6/234/234ra59/DC1 Materials and Methods

Fig. S1. The complete sequences of the heavy (A) and light (B) chain variable regions of 14 MERS-CoV RBD-specific mAbs together with their family designations.

Fig. S2. Limited degree of sequence variation in RBD region that interfaces with DPP4. Fig. S3. Polyreactivity of MERS-4 and MERS-27 against host antigens.

\section{REFERENCES AND NOTES}

1. J. F. Chan, K. S. Li, K. K. To, V. C. Cheng, H. Chen, K. Y. Yuen, Is the discovery of the novel human betacoronavirus 2C EMC/2012 (HCoV-EMC) the beginning of another SARS-like pandemic? J. Infect. 65, 477-489 (2012).

2. A. Bermingham, M. A. Chand, C. S. Brown, E. Aarons, C. Tong, C. Langrish, K. Hoschler, K. Brown, M. Galiano, R. Myers, R. G. Pebody, H. K. Green, N. L. Boddington, R. Gopal, N. Price, W. Newsholme, C. Drosten, R. A. Fouchier, M. Zambon, Severe respiratory illness caused by a novel coronavirus, in a patient transferred to the United Kingdom from the Middle East, September 2012. Euro Surveill. 17, 20290 (2012).

3. R. J. de Groot, S. C. Baker, R. S. Baric, C. S. Brown, C. Drosten, L. Enjuanes, R. A. Fouchier, M. Galiano, A. E. Gorbalenya, Z. Memish, S. Perlman, L. L. Poon, E. J. Snijder, G. M. Stephens, P. C. Woo, A. M. Zaki, M. Zambon, J. Ziebuhr, Middle East respiratory syndrome coronavirus (MERS-CoV): Announcement of the Coronavirus Study Group. J. Virol. 87, 7790-7792 (2013).

4. V. S. Raj, H. Mou, S. L. Smits, D. H. Dekkers, M. A. Müller, R. Dijkman, D. Muth, J. A. Demmers, A. Zaki, R. A. Fouchier, V. Thiel, C. Drosten, P. J. Rottier, A. D. Osterhaus, B. J. Bosch, B. L. Haagmans, Dipeptidyl peptidase 4 is a functional receptor for the emerging human coronavirus-EMC. Nature 495, 251-254 (2013).

5. The WHO MERS-CoV Research Group, State of knowledge and data gaps of Middle East respiratory syndrome coronavirus (MERS-CoV) in humans. PLOS Curr. 5, ecurrents.outbreaks. 0bf719e352e7478f8ad85fa30127ddb8 (2013).

6. A. M. Zaki, S. van Boheemen, T. M. Bestebroer, A. D. Osterhaus, R. A. Fouchier, Isolation of a nove coronavirus from a man with pneumonia in Saudi Arabia. N. Engl. J. Med. 367, 1814-1820 (2012)

7. L. Du, Y. He, Y. Zhou, S. Liu, B. J. Zheng, S. Jiang, The spike protein of SARS-CoV-A target for vaccine and therapeutic development. Nat. Rev. Microbiol. 7, 226-236 (2009).

8. R. L. Graham, E. F. Donaldson, R. S. Baric, A decade after SARS: Strategies for controlling emerging coronaviruses. Nat. Rev. Microbiol. 11, 836-848 (2013).

9. Z. A. Memish, N. Mishra, K. J. Olival, S. F. Fagbo, V. Kapoor, J. H. Epstein, R. Alhakeem, A. Durosinloun, M. Al Asmari, A. Islam, A. Kapoor, T. Briese, P. Daszak, A. A. Al Rabeeah, W. I. Lipkin, Middle East respiratory syndrome coronavirus in bats, Saudi Arabia. Emerg. Infect. Dis. 19, 1819-1823 (2013).

10. N. M. Ferguson, M. D. Van Kerkhove, Identification of MERS-CoV in dromedary camels. Lancet Infect. Dis. 14, 93-94 (2014).
11. B. L. Haagmans, S. H. Al Dhahiry, C. B. Reusken, V. S. Raj, M. Galiano, R. Myers, G. J. Godeke, M. Jonges, E. Farag, A. Diab, H. Ghobashy, F. Alhajri, M. Al-Thani, S. A. Al-Marri, H. E. Al Romaihi, A. Al Khal, A. Bermingham, A. D. Osterhaus, M. M. AlHajri, M. P. Koopmans, Middle East respiratory syndrome coronavirus in dromedary camels: An outbreak investigation. Lancet Infect. Dis. 14, 140-145 (2014).

12. R. A. Perera, P. Wang, M. R. Gomaa, R. El-Shesheny, A. Kandeil, O. Bagato, L. Y. Siu, M. M. Shehata, A. S. Kayed, Y. Moatasim, M. Li, L. L. Poon, Y. Guan, R. J. Webby, M. A. Ali, J. S. Peiris, G. Kayali, Seroepidemiology for MERS coronavirus using microneutralisation and pseudoparticle virus neutralisation assays reveal a high prevalence of antibody in dromedary camels in Egypt, June 2013. Euro Surveill. 18, 20574 (2013).

13. C. B. Reusken, B. L. Haagmans, M. A. Müller, C. Gutierrez, G. J. Godeke, B. Meyer, D. Muth, V. S. Raj, L. Smits-De Vries, V. M. Corman, J. F. Drexler, S. L. Smits, Y. E. El Tahir, R. De Sousa, J. van Beek, N. Nowotny, K. van Maanen, E. Hidalgo-Hermoso, B. J. Bosch, P. Rottier, A. Osterhaus, C. Gortázar-Schmidt, C. Drosten, M. P. Koopmans, Middle East respiratory syndrome coronavirus neutralising serum antibodies in dromedary camels: A comparative serological study. Lancet Infect. Dis. 13, 859-866 (2013).

14. M. Cotten, S. J. Watson, P. Kellam, A. A. Al-Rabeeah, H. Q. Makhdoom, A. Assiri, J. A. Al-Tawfiq, R. F. Alhakeem, H. Madani, F. A. AlRabiah, S. Al Hajjar, W. N. Al-nassir, A. Albarrak, H. Flemban, H. H. Balkhy, S. Alsubaie, A. L. Palser, A. Gall, R. Bashford-Rogers, A. Rambaut, A. I. Zumla, Z. A. Memish, Transmission and evolution of the Middle East respiratory syndrome coronavirus in Saudi Arabia: A descriptive genomic study. Lancet 382, 1993-2002 (2013).

15. S. K. Lau, K. S. Li, A. K. Tsang, C. S. Lam, S. Ahmed, H. Chen, K. H. Chan, P. C. Woo, K. Y. Yuen, Genetic characterization of Betacoronavirus lineage $C$ viruses in bats reveals marked sequence divergence in the spike protein of Pipistrellus bat coronavirus HKU5 in Japanese pipistrelle: Implications for the origin of the novel Middle East respiratory syndrome coronavirus. J. Virol. 87, 8638-8650 (2013).

16. S. van Boheemen, M. de Graaf, C. Lauber, T. M. Bestebroer, V. S. Raj, A. M. Zaki, A. D. Osterhaus, B. L. Haagmans, A. E. Gorbalenya, E. J. Snijder, R. A. Fouchier, Genomic characterization of a newly discovered coronavirus associated with acute respiratory distress syndrome in humans. MBio 3, e00473-12 (2012).

17. P. C. Y. Woo, S. K. P. Lau, K. S. M. Li, A. K. L. Tsang, K. Y. Yuen, Genetic relatedness of the novel human group $\mathrm{C}$ betacoronavirus to Tylonycteris bat coronavirus HKU4 and Pipistrellus bat coronavirus HKU5. Emerg. Microbes Infect. 1, e35 (2012).

18. J. F. Chan, K. K. To, H. Tse, D. Y. Jin, K. Y. Yuen, Interspecies transmission and emergence of novel viruses: Lessons from bats and birds. Trends Microbiol. 21, 544-555 (2013).

19. J. F. Chan, K. H. Chan, G. K. Choi, K. K. To, H. Tse, J. P. Cai, M. L. Yeung, V. C. Cheng, H. Chen, X. Y. Che, S. K. Lau, P. C. Woo, K. Y. Yuen, Differential cell line susceptibility to the emerging novel human betacoronavirus 2c EMC/2012: Implications for disease pathogenesis and clinical manifestation. J. Infect. Dis. 207, 1743-1752 (2013).

20. P. C. Woo, M. Wang, S. K. Lau, H. Xu, R. W. Poon, R. Guo, B. H. Wong, K. Gao, H. W. Tsoi, Y. Huang, K. S. Li, C. S. Lam, K. H. Chan, B. J. Zheng, K. Y. Yuen, Comparative analysis of twelve genomes of three novel group $2 c$ and group $2 \mathrm{~d}$ coronaviruses reveals unique group and subgroup features. J. Virol. 81, 1574-1585 (2007).

21. Z. A. Memish, A. I. Zumla, R. F. Al-Hakeem, A. A. Al-Rabeeah, G. M. Stephens, Family cluster of Middle East respiratory syndrome coronavirus infections. N. Engl. J. Med. 368, 2487-2494 (2013).

22. A. Assiri, A. McGeer, T. M. Perl, C. S. Price, A. A. Al Rabeeah, D. A. Cummings, Z. N. Alabdullatif, M. Assad, A. Almulhim, H. Makhdoom, H. Madani, R. Alhakeem, J. A. Al-Tawfiq, M. Cotten, S. J. Watson, P. Kellam, A. I. Zumla, Z. A. Memish; KSA MERS-CoV Investigation Team, Hospital outbreak of Middle East respiratory syndrome coronavirus. N. Engl. J. Med. 369, 407-416 (2013).

23. D. Falzarano, E. de Wit, A. L. Rasmussen, F. Feldmann, A. Okumura, D. P. Scott, D. Brining, T. Bushmaker, C. Martellaro, L. Baseler, A. G. Benecke, M. G. Katze, V. J. Munster, H. Feldmann, Treatment with interferon- $\alpha 2 \mathrm{~b}$ and ribavirin improves outcome in MERS-CoV-infected rhesus macaques. Nat. Med. 19, 1313-1317 (2013).

24. J. A. Al-Tawfiq, H. Momattin, J. Dib, Z. A. Memish, Ribavirin and interferon therapy in patients infected with the Middle East respiratory syndrome coronavirus: An observational study. Int. J. Infect. Dis. 20, 42-46 (2014).

25. J. F. Chan, K. H. Chan, R. Y. Kao, K. K. To, B. J. Zheng, C. P. Li, P. T. Li, J. Dai, F. K. Mok, H. Chen, F. G. Hayden, K. Y. Yuen, Broad-spectrum antivirals for the emerging Middle East respiratory syndrome coronavirus. J. Infect. 67, 606-616 (2013).

26. L. Lu, Q. Liu, Y. Zhu, K. H. Chan, L. Qin, Y. Li, Q. Wang, J. F. Chan, L. Du, F. Yu, C. Ma, S. Ye, K. Y. Yuen, R. Zhang, S. Jiang, Structure-based discovery of Middle East respiratory syndrome coronavirus fusion inhibitor. Nat. Commun. 5, 3067 (2014).

27. S. K. Lau, C. C. Lau, K. H. Chan, C. P. Li, H. Chen, D. Y. Jin, J. F. Chan, P. C. Woo, K. Y. Yuen, Delayed induction of proinflammatory cytokines and suppression of innate antiviral response by the novel Middle East respiratory syndrome coronavirus: Implications for pathogenesis and treatment. J. Gen. Virol. 94, 2679-2690 (2013).

28. J. Zhou, H. Chu, C. Li, B. H. Wong, Z. S. Cheng, V. K. Poon, T. Sun, C. C. Lau, K. K. Wong, J. Y. Chan, J. F. Chan, K. K. To, K. H. Chan, B. J. Zheng, K. Y. Yuen, Active replication of Middle East respiratory syndrome coronavirus and aberrant induction of inflammatory cytokines and 
chemokines in human macrophages: Implications for pathogenesis. J. Infect. Dis. 209, 1331-1342 (2014).

29. P. S. Masters, The molecular biology of coronaviruses. Adv. Virus Res. 66, 193-292 (2006).

30. S. R. Weiss, S. Navas-Martin, Coronavirus pathogenesis and the emerging pathogen severe acute respiratory syndrome coronavirus. Microbiol. Mol. Biol. Rev. 69, 635-664 (2005).

31. K. H. Chan, J. F. Chan, H. Tse, H. Chen, C. C. Lau, J. P. Cai, A. K. Tsang, X. Xiao, K. K. To, S. K. Lau, P. C. Woo, B. J. Zheng, M. Wang, K. Y. Yuen, Cross-reactive antibodies in convalescent SARS patients' sera against the emerging novel human coronavirus EMC (2012) by both immunofluorescent and neutralizing antibody tests. J. Infect. 67, 130-140 (2013).

32. G. Lu, Y. Hu, Q. Wang, J. Qi, F. Gao, Y. Li, Y. Zhang, W. Zhang, Y. Yuan, J. Bao, B. Zhang, Y. Shi, J. Yan, G. F. Gao, Molecular basis of binding between novel human coronavirus MERS-CoV and its receptor CD26. Nature 500, 227-231 (2013).

33. N. Wang, X. Shi, L. Jiang, S. Zhang, D. Wang, P. Tong, D. Guo, L. Fu, Y. Cui, X. Liu, K. C. Arledge, Y. H. Chen, L. Zhang, X. Wang, Structure of MERS-CoV spike receptor-binding domain complexed with human receptor DPP4. Cell Res. 23, 986-993 (2013).

34. K. Ohnuma, B. L. Haagmans, R. Hatano, V. S. Raj, H. Mou, S. Iwata, N. H. Dang, B. Jan Bosch, C. Morimoto, Inhibition of Middle East respiratory syndrome coronavirus infection by antiCD26 monoclonal antibody. J. Virol. 87, 13892-13899 (2013).

35. K. Ohnuma, N. H. Dang, C. Morimoto, Revisiting an old acquaintance: CD26 and its molecular mechanisms in T cell function. Trends Immunol. 29, 295-301 (2008).

36. L. Du, Z. Kou, C. Ma, X. Tao, L. Wang, G. Zhao, Y. Chen, F. Yu, C. T. Tseng, Y. Zhou, S. Jiang, A truncated receptor-binding domain of MERS-CoV spike protein potently inhibits MERS-CoV infection and induces strong neutralizing antibody responses: Implication for developing therapeutics and vaccines. PLOS One 8, e81587 (2013).

37. L. Du, G. Zhao, Z. Kou, C. Ma, S. Sun, V. K. Poon, L. Lu, L. Wang, A. K. Debnath, B. J. Zheng, Y. Zhou, S. Jiang, Identification of a receptor-binding domain in the $S$ protein of the novel human coronavirus Middle East respiratory syndrome coronavirus as an essential target for vaccine development. J. Virol. 87, 9939-9942 (2013).

38. F. Song, R. Fux, L. B. Provacia, A. Volz, M. Eickmann, S. Becker, A. D. Osterhaus, B. L. Haagmans, G. Sutter, Middle East respiratory syndrome coronavirus spike protein delivered by modified vaccinia virus ankara efficiently induces virus-neutralizing antibodies. J. Virol. 87, 11950-11954 (2013).

39. H. Mou, V. S. Raj, F. J. van Kuppeveld, P. J. Rottier, B. L. Haagmans, B. J. Bosch, The receptor binding domain of the new Middle East respiratory syndrome coronavirus maps to a 231residue region in the spike protein that efficiently elicits neutralizing antibodies. J. Virol. 87, 9379-9383 (2013).

40. G. Chao, W. L. Lau, B. J. Hackel, S. L. Sazinsky, S. M. Lippow, K. D. Wittrup, Isolating and engineering human antibodies using yeast surface display. Nat. Protoc. 1, 755-768 (2006).

41. M. J. Feldhaus, R. W. Siegel, L. K. Opresko, J. R. Coleman, J. M. Feldhaus, Y. A. Yeung, J. R. Cochran, P. Heinzelman, D. Colby, J. Swers, C. Graff, H. S. Wiley, K. D. Wittrup, Flow-cytometric isolation of human antibodies from a nonimmune Saccharomyces cerevisiae surface display library. Nat. Biotechnol. 21, 163-170 (2003).

42. T. C. Chou, Drug combination studies and their synergy quantification using the Chou-Talalay method. Cancer Res. 70, 440-446 (2010).

43. T. C. Chou, P. Talalay, Quantitative analysis of dose-effect relationships: The combined effects of multiple drugs or enzyme inhibitors. Adv. Enzyme Regul. 22, 27-55 (1984).
44. Z. Keck, W. Wang, Y. Wang, P. Lau, T. H. Carlsen, J. Prentoe, J. Xia, A. H. Patel, J. Bukh, S. K. Foung, Cooperativity in virus neutralization by human monoclonal antibodies to two adjacent regions located at the amino terminus of hepatitis C virus E2 glycoprotein. J. Virol. 87, 37-51 (2013).

45. A. Assiri, J. A. Al-Tawfiq, A. A. Al-Rabeeah, F. A. Al-Rabiah, S. Al-Hajjar, A. Al-Barrak, H. Flemban, W. N. Al-Nassir, H. H. Balkhy, R. F. Al-Hakeem, H. Q. Makhdoom, A. I. Zumla, Z. A. Memish, Epidemiological, demographic, and clinical characteristics of 47 cases of Middle East respiratory syndrome coronavirus disease from Saudi Arabia: A descriptive study. Lancet Infect. Dis. 13, 752-761 (2013).

46. P. C. Wilson, S. F. Andrews, Tools to therapeutically harness the human antibody response. Nat. Rev. Immunol. 12, 709-719 (2012).

47. R. L. Graham, R. S. Baric, Recombination, reservoirs, and the modular spike: Mechanisms of coronavirus cross-species transmission. J. Virol. 84, 3134-3146 (2010).

48. B. J. Zheng, K. W. Chan, Y. P. Lin, G. Y. Zhao, C. Chan, H. J. Zhang, H. L. Chen, S. S. Wong, S. K. Lau, P. C. Woo, K. H. Chan, D. Y. Jin, K. Y. Yuen, Delayed antiviral plus immunomodulator treatment still reduces mortality in mice infected by high inoculum of influenza $A / H 5 N 1$ virus. Proc. Natl. Acad. Sci. U.S.A. 105, 8091-8096 (2008).

49. L. Du, Y. He, Y. Wang, H. Zhang, S. Ma, C. K. Wong, S. H. Wu, F. Ng, J. D. Huang, K. Y. Yuen, S. Jiang, Y. Zhou, B. J. Zheng, Recombinant adeno-associated virus expressing the receptorbinding domain of severe acute respiratory syndrome coronavirus $S$ protein elicits neutralizing antibodies: Implication for developing SARS vaccines. Virology 353, 6-16 (2006).

Acknowledgments: We are grateful to C. Baird (Pacific Northwest National Laboratory) for providing the human nonimmune scFv library, J. Mascola (Vaccine Research Center, NIH) for providing mAb VRC01, M. C. Nussenzweig (Rockefeller University, New York) for providing the antibody expression vector, and R. Fouchier (Erasmus University Medical Center Rotterdam) for providing the MERS-CoV (hCoV-EMC) isolate. We also thank D. Wang for help in the SPR experiment. Funding: This study is supported by the Tsinghua University Initiative Scientific Research Program (20124812029), funds from Ministry of Science and Technology of China (2014CB542500-03, 2011CB910502) and also in part by the National Institute of Allergy and Infectious Diseases, U.S. $\mathrm{NIH}$ (Comprehensive International Program for Research on AIDS grant U19 AI51915). Author contributions: All authors contributed to the current study, including intellectual input, results analysis, and actual writing and editing of the manuscript. Specifically, L.J., N.W., K.-Y.Y., B.-J.Z., X.W., and L.Z. designed the study and L.J., N.W., T.Z., X.S., K.-M.V.P., Y.W., F.G., D.L., R.W., J.G., and L.F. performed the experiments. L.J., N.W., B.-J.Z., X.W., and L.Z. analyzed the data and wrote the paper. Competing interests: A patent application has been submitted for the MERS- 4 and MERS-27 antibodies. The authors declare that they have no other competing interests. Data and materials availability: The MERS-4 and MERS- 27 mAbs may be obtained through a materials transfer agreement.

Submitted 26 November 2013

Accepted 5 March 2014

Published 30 April 2014

$10.1126 /$ scitranslmed. 3008140

Citation: L. Jiang, N. Wang, T. Zuo, X. Shi, K.-M. V. Poon, Y. Wu, F. Gao, D. Li, R. Wang, J. Guo, L. Fu, K.-Y. Yuen, B.-J. Zheng, X. Wang, L. Zhang, Potent neutralization of MERS-CoV by human neutralizing monoclonal antibodies to the viral spike glycoprotein. Sci. Transl. Med. 6, 234ra59 (2014). 


\section{Abstracts}

One-sentence summary: Human neutralizing monoclonal antibody could serve as a therapeutic intervention against MERS-CoV infection.

\section{Editor's Summary: Neutralizing MERS-CoV}

A camel gets sick, and infects a man. A health care worker succumbs. A migrant laborer gets off a plane thousands of miles away, unaware that he's infected. This may sound like a trailer for the latest pandemic thriller, but for people infected with Middle East respiratory syndrome coronavirus (MERS-CoV), the story hits close to home. MERS-CoV is an emerging infection that causes severe and fatal acute respiratory illness in humans. Although the number of people infected to date remains small, the high mortality rate (currently estimated at around 40\%) and clusters of human-to-human transmission raise concerns of a MERS-CoV pandemic. What's more, no MERS-CoV-specific therapy or vaccine is currently available. Now, Jiang et al. report the development of human monoclonal neutralizing antibodies to MERS-CoV with the potential to treat human patients.

MERS-CoV enters target cells through binding of the receptor binding domain (RBD) of the viral envelope spike glycoprotein to the cellular receptor dipeptidyl peptidase 4 (DPP4). The authors therefore developed antibodies against this RBD in an effort to block cell-to-cell transmission. Two of these antibodies inhibited infection of MERS-CoV variants in vitro by blocking the interaction of the RBD with DPP4. These antibodies recognize distinct regions of RBD and can work in concert. Although the antibodies still need to be tested in both animal and human trials, they provide hope for a therapy for a potentially emerging pandemic where none currently exists. 